\title{
Antarctic blue whales (Balaenoptera musculus intermedia) recorded at the Equator in the Atlantic Ocean
}

\author{
Samaran Flore ${ }^{1,}{ }^{*}$, Berne Adrien ${ }^{1,5}$, Leroy Emmanuelle C ${ }^{2}$, Moreira Sérgio ${ }^{3}$, Stafford Kathleen M. ${ }^{4}$, \\ Maia Marcia ${ }^{2}$, Royer Jean-Yves ${ }^{2,5}$
}

1 ENSTA Bretagne, UMR CNRS 6285 Lab-STICC 29806 Brest Cedex 9, France

2 University of Brest-CNRS Laboratoire Géosciences Océan, IUEM; Plouzané, 29280, France

${ }^{3}$ National Museum, Department of Vertebrates; Federal University of Rio de Janeiro; Rio de Janeiro, 21941-90, Brazil

${ }^{4}$ Applied Physics Laboratory; University of Washington; Seattle, Washington, 98195 ,U.S.A.

* Corresponding author : Flore Samaran, email address : flore.samaran@ensta-bretagne.fr 
Antarctic blue whales (Balaenoptera musculus intermedia) are slowly recovering from decades of commercial whaling in the Southern Hemisphere that brought the species to the brink of extinction by the 1970s (Branch et al. 2004, 2007; Thomas et al. 2015). In general, these whales spend the austral summer around the Antarctic and migrate northwards in winter, although there is evidence from both whaling-era data and modern passive acoustic monitoring that some animals remain at high latitudes in winter (Hinton 1915, Širović et al. 2004, Thomisch et al. 2016). The northernmost-documented wintering destinations of Antarctic blue whales include the west coast of Africa up to Angola (Best 1998, Figueiredo and Weir 2014), the eastern tropical Pacific (Stafford et al. 2004), off northern New Zealand (McDonald 2006), and the Indian Ocean near the Diego Garcia atoll (Stafford et al. 2004).

Most current knowledge about the occurrence of Antarctic blue whales comes from passive acoustic data sets from hydrophones deployed from high to low latitudes (Antarctic deployments reviewed in van Opzeeland et al. 2013; for lower latitudes see Stafford et al. 2004, McDonald 2006, Samaran et al. 2013, Tsang-Hin-Sun et al. 2015, Leroy et al. 2016). This approach has proved very effective for monitoring Antarctic blue whales as they produce a distinct low frequency signal, known as the Z-call, easily recognizable from its Z-shape in the time-frequency domain (Fig. 1A; Ljungblad et al. 1998, Rankin et al. 2005, Širović et al. 2009). Densely produced Z-calls from distant Antarctic blue whales can create a 'chorus' of energy 
between 28 and $26 \mathrm{~Hz}$ (Fig. 1B). Both calls and choruses have been used to identify regions and seasons of occurrence for this species (e.g., Širović et al. 2009, Thomisch et al. 2016, Leroy et al. 2016). Here, we present the first evidence of the surprising seasonal presence of Antarctic blue whales at the Equator in the Atlantic Ocean.

In 2013, three hydrophones were deployed on moorings in the equatorial Atlantic Ocean during the COLMEIA-HYDRO acoustic experiment (Maia 2013; Fig. 2). The instruments, developed by the Laboratoire Geosciences Océan (Brest, France), consisted of hydrophones connected to autonomous acquisition and storage systems (D’Eu et al. 2012). Each instrument was moored in the axis of the sound fixing and ranging (SOFAR) channel. The acoustic data were digitized at a sample rate of $240 \mathrm{~Hz}$ using a 24-bit analog-to-digital conversion. The hydrophone sensitivity was $-163.5 \mathrm{~dB}$ re: $1 \mathrm{~V} / \mathrm{Pa}$, including preamplifier gain. Upon recovery, the data were downloaded and examined via long-term spectrograms. The records at the three sites clearly show a band of energy between 26 and $26.5 \mathrm{~Hz}$ throughout the year (Fig. 3). This band indicates the presence of the Antarctic blue whale chorus resulting from the first unit of Z-calls. The energetic bandwidth near 17-22 Hz represents a combination of Antarctic blue whales Z-calls, fin whale $20 \mathrm{~Hz}$-pulses, and possibly Atlantic blue whale calls (16-18 Hz, Mellinger and Clark 2003).

To more closely analyze the presence of Antarctic blue whale calls, two metrics were used: the number of distinct Z-calls or call counts, and the power of the Antarctic blue whale chorus. Indeed, a lack of individual call detections does not necessarily mean an absence of calling whales; a "loud" Antarctic blue whale chorus suggests that whales are present in the area, but not close enough to the hydrophone for individual calls to be distinct.

Z-calls were automatically detected using the "Z-detector", a subspace-detection algorithm specifically developed to detect Antarctic blue whale Z-calls (Socheleau et al. 2015). Because potentially masking signals (airguns, ship noise and Antarctic blue whale chorus) occur in the data set and can therefore result in false detections of Antarctic blue whale Z-calls, all detections were visually checked. All false detections were deleted and not considered further in this analysis. The number of remaining calls detected certainly underestimated the total number of recorded calls, since faint or noise-masked calls were either deleted or not detected. The total number of detected calls were summed and plotted per week (Fig. 4). To complement the observation, the chorus level (in $\mathrm{dB}$ re $1 \mu \mathrm{Pa}^{2} / \mathrm{Hz}$ ) was calculated as the energy in the frequency band of $25.5-26.5 \mathrm{~Hz}$ minus the noise level in the 30-33 Hz frequency range, just 
above the chorus (see Leroy et al. 2016). This Chorus to Noise-without-chorus Ratio (CNR) was then averaged per week (Fig. 4).

The CNR at all sites showed a clear seasonal variation with a peak from May to July 2013 (Fig. 4). The CNR levels were very similar among the 3 sites except for a few weeks between midMay and mid-June where the level was somewhat higher at the eastern site (C4).

At C2 and C4, very few and only faint individual Z-calls were detected, while at C5, over 1,144 individual clear Z-calls were detected. The calls recorded at C5 were not detected at the same time, or within the time frame required to travel from one hydrophone to another, as the faint calls recorded at C2 and C4. Calls in the vicinity of C5 were regularly detected during the austral winter (June-September; Fig. 4). The greatest number of detections, however, occurred over a 2-day period in July (15-16 July) with a total of 637 calls ( $56 \%$ of the total number of detections). During 9 consecutive hours 382 Antarctic blue whale Z-calls were detected with high signal-tonoise ratios suggesting the singing blue whale(s) was (were) relatively close to the hydrophone. During this short period, Z-calls were repeated at very regular inter-call intervals (mean $73.5 \mathrm{~s}$ from the start of a call to the start of the next call). Songs were sometimes interrupted by longer intervals of $\sim 189 \mathrm{~s}(116-311 \mathrm{~s}, n=32)$. The CNR peak occurred a month before the distinct series of calls (mid-June 2013).

Detection ranges of Antarctic blue whale individual Z-calls and chorus are difficult to estimate. The range will depend on the environmental conditions (ambient noise levels, sound propagation) that can change seasonally, and on the depth and source levels of calling whales. Estimated detection distances for individual blue whale calls from other hydrophones deployed in the SOFAR channel have ranged from 10-200 km (Stafford et al. 2007, Samaran et al. 2010). Based on simple Monte Carlo estimations for the COLMEIA location, individual Z-calls with good SNR were likely produced by whales within a few tens kilometers of the hydrophones. Beyond this distance, clear Z-calls can occasionally be distinguished but propagation effects likely alter the shape of the signal and/or merge many Z-calls into a chorus making individual Z-calls indistinguishable. Beyond a few hundred kilometers, Z-calls contribute to the ocean soundscape only as a chorus (R. Emmetière, pers. comm. 2017¹). As the loudest series of individual calls and songs were only recorded on one of the three hydrophones, and the two closest hydrophones were $360 \mathrm{~km}$ apart, the whale(s) producing the loudest songs could not

\footnotetext{
${ }^{1}$ R. Emmetière ENSTA Bretagne 2 rue François Verny 29490 Brest Cedex 9, May 2017
} 
have been more than half this distance away (i.e., $180 \mathrm{~km}$ ) or they would have been recorded on more than a single hydrophone. Even though we cannot tell how far, within this $180-\mathrm{km}$ radius, the calling animals were from the hydrophones, the detection of distinct, loud individual Z-calls and songs suggests that Antarctic blue whales were present near our hydrophones at the Equator and were contributing to the underwater soundscape.

The COLMEIA-HYDRO data are of particular interest since they were collected in a region with a high seasonal productivity, but where only few catches, sightings, or strandings of blue whales are reported (Branch et al. 2007). Only a single blue whale was recorded from the northeastern South Atlantic in whaling records off modern-day Gabon in 1926 (Mackintosh 1942). Three blue whales were sighted off the coast of Paraíba $\left(7^{\circ} \mathrm{S}\right)$, during commercial hunting seasons, between 1966 and 1981 (da Rocha 1983) and two blue whales were captured commercially in Paraíba, in 1948 and 1965, and one in Rio de Janeiro (23ㅇㄱ), in 1962 (Zerbini et al. 1997). In 1992, a 23 m long female stranded in Rio Grande do Sul (30S; Dalla Rosa and Secchi 1997). Most recently, an adult and a young blue whale were sighted twice on 27 and 31 July, 2011, in Rio Grande do Norte $\left(6^{\circ} \mathrm{S}\right.$; de Oliveira 2015). It is not known whether these were Antarctic blue whales.

The COLMEIA-HYDRO records provide the northern-most evidence for a presence of Antarctic blue whales and the longest seasonality of this species at low latitudes. Based on their calling patterns, the bulk of the detected loud calls were likely produced by relatively few animals. One could assume that the songs recorded on 15 and 16 July 2013 were from a single individual in the vicinity of the hydrophone. In the South Atlantic, Antarctic blue whales are recorded yearround near Ascension Island (756’S 14²5’W; Haver et al. 2017). In the Indian and eastern tropical Pacific Oceans, Antarctic blue whale calls were recorded at $8^{\circ} \mathrm{S}$ only in the austral winter and in each of these locations, in limited numbers and over relatively few days (Stafford et al. 2004). However, the records presented here come one to two decades after these studies, and suggest that in the interim the global population of Antarctic blue whales has continued to grow and spread. The circum-Antarctic blue whale population was estimated at 2,280 individuals in 1998 (Branch 2007), and its best growth rate at 7.3\% per year (Branch et al. 2004). In the intervening 2 decades since then, the population may have increased to well over 8,000 Antarctic blue whales. It is therefore entirely possible that this species has expanded its habitat both spatially and temporally around Antarctica and as far north as the Equator in the Atlantic, Pacific and Indian Oceans. However, the absence of individual Z-calls at $4^{\circ} \mathrm{S}$ in the 
Indian Ocean, in 2012-2013 (Leroy et al. 2016), suggest that Antarctic blue whales have not yet migrated that far north.

\section{ACKNOWLEDGMENTS}

The authors wish to thank the captains and crews of RV Atalante and NPAOC Araguari for the deployment and recovery, resp., of the COLMEIA-HYDRO hydrophones. These expeditions were funded by the French Ministry of Research and the Brazilian Navy, with additional support for the hydroacoustic experiment from CNRS-INSU, the Labex Mer and the Regional Council of Brittany. We are grateful to SECIRM, Brazilian Navy, for their help and support to this project.

\section{LITERATURE CITED}

Best, P. B. 1998. Blue whales off Namibia - a possible wintering ground for the Antarctic population. Paper SC/50/CAWS14 presented to the IWC Scientific Committee, April 1998, Muscat, Oman (Available from IWC, The Red House, 135 Station Road, Impington, Cambridge, CB4 9NP, UK).

Branch, T. 2007. Abundance of Antarctic blue whales south of $60 \mathrm{~S}$ from three complete circumpolar sets of surveys. Journal of Cetacean Research and Management 9: 253-262.

Branch, T., K. Matsuoka and T. Miyashita. 2004. Evidence for increases in Antarctic blue whales based on Bayesian modelling. Marine Mammal Science 20: 726-754.

Branch, T., K. M. Stafford, D. M. Palacios, et al. 2007. Past and present distribution, densities and movements of blue whales Balaenoptera musculus in the Southern Hemisphere and northern Indian Ocean. Mammal Review 37: 116-175.

da Rocha, J. M. 1983. Revision of Brazilian whaling data. Reports of the International Whaling Commission 33: 419-427.

Dalla Rosa, L. and E. R. Secchi. 1997. Stranding of a blue whale (Balaenoptera musculus) in southern Brazil: "True" or pygmy. Report of the International Whaling Commission 47: 425-430.

de Oliveira, I. T. G. 2015. Diversidade e comportamento de cetáceos associado a embarcações na bacia Potiguar, Rio Grande do Norte - Brasil. Natal, Rio Grande do Norte. Master thesis. Federal University of Rio Grande do Norte. Available from https://repositorio.ufrn.br/jspui/handle/123456789/22005

D'Eu, J.-F., J.-Y. Royer and J. Perrot. 2012. Long-term autonomous hydrophones for large-scale hydroacoustic monitoring of the oceans. Pages 1-6 in Proceedings of Oceans 2012, IEEE, Yeosu (Korea).

Figueiredo, I and C. R. Weir. 2014. Blue whales Balaenoptera musculus off Angola: recent sightings and evaluation of whaling data. African Journal of Marine Science, 36: 269-278.

Haver S. A., H. Klinck, S. I. Nieukirk, H. Matsumoto, R. P. Dziak, and J. L. Miksis-Olds. 2017. The not-so-silent world: Measuring Arctic, Equatorial, and Antarctic soundscapes in the Atlantic Ocean. Deep-Sea Research I 122: 95104.

Hinton M. A. C. 1915. Appendix VII. Report on the papers left by the late Major Barrett- Hamilton relating to the whales of South Georgia. Pages 69-209 in Inter-departmental committee on whaling and the protection of whales. Colonial Office Misc. No. 298. Crown Agents for the Colonies, London, UK.

Leroy, E. C., F. Samaran, J. Bonnel and J.-Y. Royer. 2016. Seasonal and diel vocalization patterns of Antarctic blue whale (Balaenoptera musculus intermedia) in the southern Indian Ocean: A multi-year and multi-site Study. PLoS ONE 11: e0163587.

Ljungblad, D. K., C. W. Clark and H. Shimada. 1998. A comparison of sounds attributed to pygmy blue whales (Balaenoptera musculus brevicauda) recorded south of the Madagascar Plateau and those attributed to "true" blue whales (Balaenoptera musculus) recorded off Antarctica. Reports of the International Whaling Commission 48: 439-442.

Mackintosh, N. A. 1942. The southern stocks of whalebone whales. Discovery Reports 22: 197-300. 
Maia, M. 2013. COLMEIA cruise, RV Atalante, http://dx.doi.org/10.17600/13010010.

McDonald, M. A. 2006. An acoustic survey of baleen whales off Great Barrier Island, New Zealand. New Zealand Journal of Marine and Freshwater Research 40: 519-529.

Mellinger, D., and C. Clark. 2003. Blue whale (Balaenoptera musculus) sounds from the North Atlantic. Journal of the Acoustical Society of America 114: 1108-1119.

Rankin, S., D. Ljungblad, C. Clark, and H. Kato. 2005. Vocalisations of Antarctic blue whales, Balaenoptera musculus intermedia, recorded during the 2001/2002 and 2002/2003 IWC/SOWER circumpolar cruises, Area V, Antarctica. Journal of Cetacean Research and Management 7: 13-20.

Samaran, F., C. Guinet,, O. Adam, J.-F. Motsch, and Y. Cansi. 2010. Source level estimation of two blue whale subspecies in southwestern Indian Ocean. Journal of the Acoustical Society of America 127: 3800-3808.

Samaran, F., K. M. Stafford, T. A. Branch, J. Gedamke, J.-Y. Royer, R.P. Dziak, and C. Guinet. 2013. Seasonal and geographic variation of southern blue whale subspecies in the Indian Ocean. PLoS ONE 8: e71561.

Širović, A., J. A. Hildebrand, S. M. Wiggins, M. A. McDonald, S. E. Moore, and D. Thiele. 2004. Seasonality of blue and fin whale calls and the influence of sea ice in the Western Antarctic Peninsula. Deep Sea Research Part II: Topical Studies in Oceanography 51: 2327-2344.

Širović, A., J. A. Hildebrand, S. M. Wiggins, and D. Thiele. 2009. Blue and fin whale acoustic presence around Antarctica during 2003 and 2004. Marine Mammal Science 25: 125-136.

Socheleau, F.-X., E. Leroy, A. Carvallo Pecci, F. Samaran, J. Bonnel, and J.-Y. Royer. 2015. Automated detection of Antarctic blue whale calls. Journal of the Acoustical Society of America 138: 3105-3117.

Stafford, K. M., D. R. Bohnenstiehl, M. Tolstoy, E. Chapp, D. K. Mellinger, and S. E. Moore. 2004. Antarctic-type blue whale calls recorded at low latitudes in the Indian and eastern Pacific Oceans. Deep Sea Research Part I: Oceanographic Research Papers 51: 1337-1346.

Stafford, K. M., D. K. Mellinger, S. E. Moore, and C.G. Fox. 2007. Seasonal variability and detection range modeling of baleen whale calls in the Gulf of Alaska, 1999-2002. Journal of the Acoustical Society of America 122: 33783390.

Thomas, P. O., R. R. Reeves, and R. L. Brownell Jr. 2015. Status of the world's baleen whales. Marine Mammal Science 32: $682-734$.

Thomisch, K., O. Boebel, C. W. Clark, W. Hagen, S. Spiesecke, D. P. Zitterbart, and I. van Opzeeland 2016. Spatiotemporal patterns in acoustic presence and distribution of Antarctic blue whales Balaenoptera musculus intermedia in the Weddell Sea. Endangered Species Research 30: 239-253.

Tsang-Hin-Sun, E., J.-Y. Royer, and E. C. Leroy. 2015. Low-frequency sound level in the Southern Indian Ocean. The Journal of the Acoustical Society of America 138: 3439-3446.

van Opzeeland, I., F. Samaran, K. M. Stafford, K. Findlay, J. Gedamke, D. Harris, and B. S. Miller 2013. Towards Collective circum-Antarctic Passive Acoustic Monitoring: The Southern Ocean Hydrophone Network (SOHN). Polarforschung 83:47-61.

Zerbini, A. N., E. R. Secchi, S. Siciliano, and P. C. Simoes-Lopes. 1997. A review of the occurrence and distribution of whales of the Genus Balaenoptera along the Brazilian coast. Reports of the International Whaling Commission 47:407-417. 
FIGURES

A)

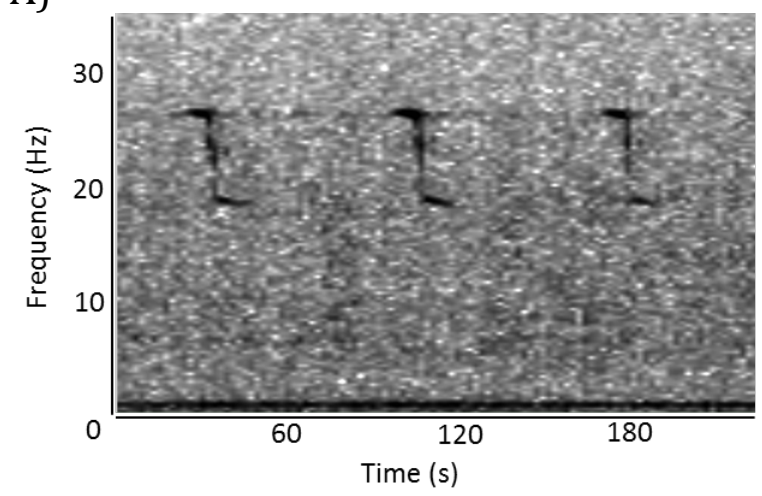

B)

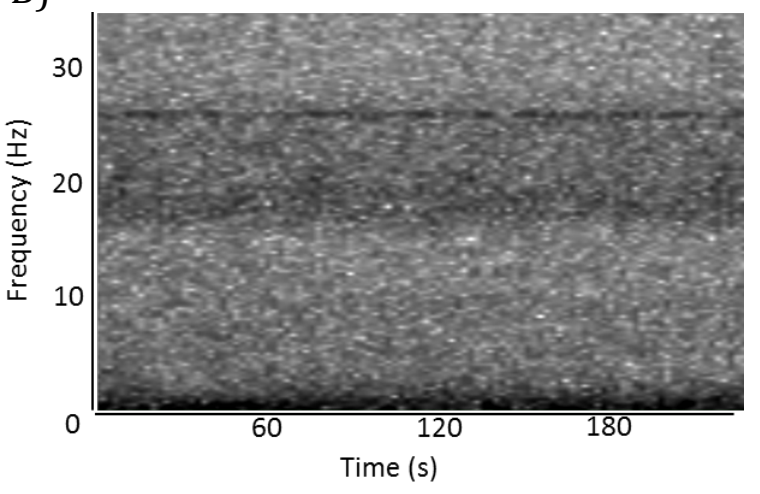

Figure 1: Spectrograms of (A) three typical Antarctic blue whale Z-calls recorded on 16 July 2013 at C5 and (B) 'chorus' of Antarctic blue whale calls, seen as a dark line near $26 \mathrm{~Hz}$ with an energetic bandwidth down to $18 \mathrm{~Hz}$, recorded on 18 June 2013 at C5 (Spectrogram parameters: FFT 1,024 points, Hamming window, 90\% overlap).

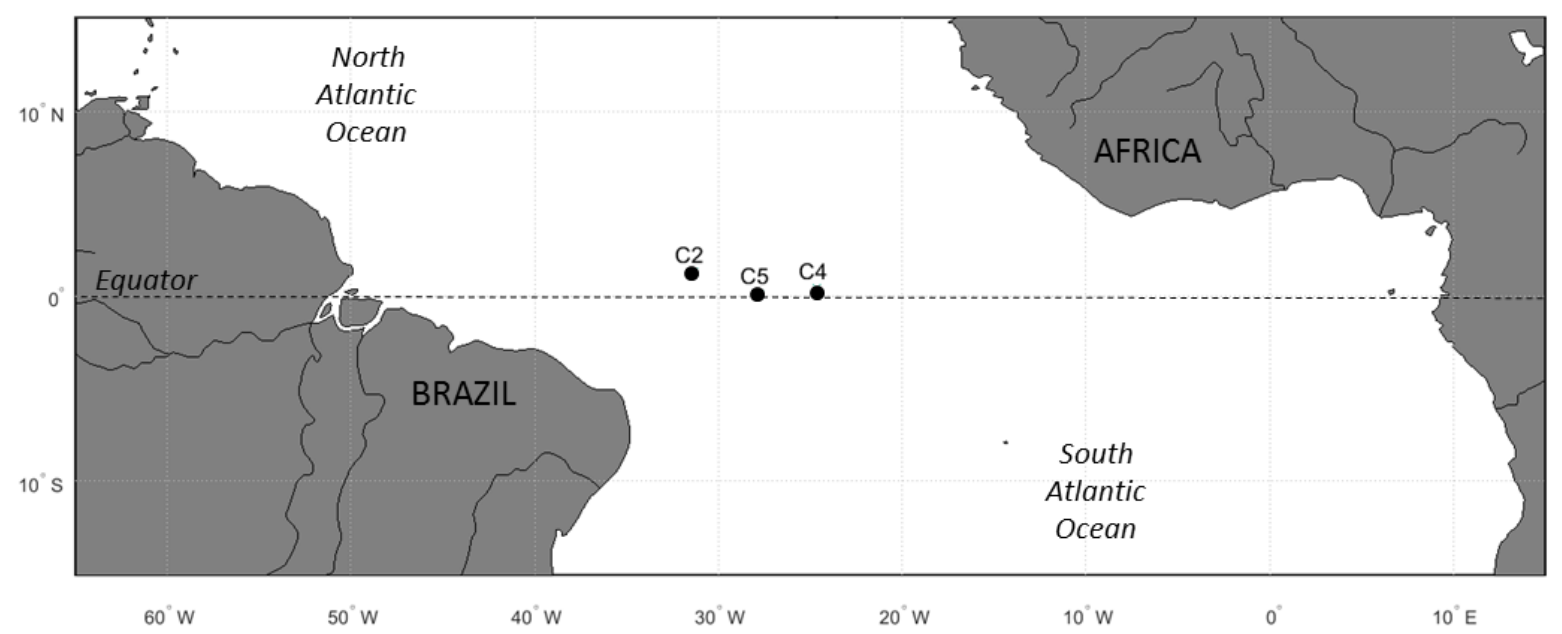

Figure 2: Locations of the hydrophones during the COLMEIA-HYDRO acoustic experiment in the Equatorial Atlantic Ocean. Hydrophone deployments: C2: $01^{\circ} 20^{\prime} \mathrm{N} 031^{\circ} 21^{\prime} \mathrm{W}$ from $02 \mathrm{Feb}$

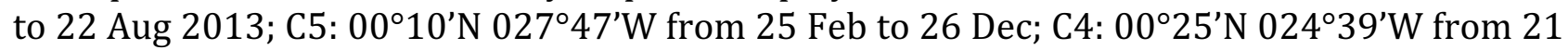
Feb to 13 Sep 2013. 
$\mathrm{C} 2$

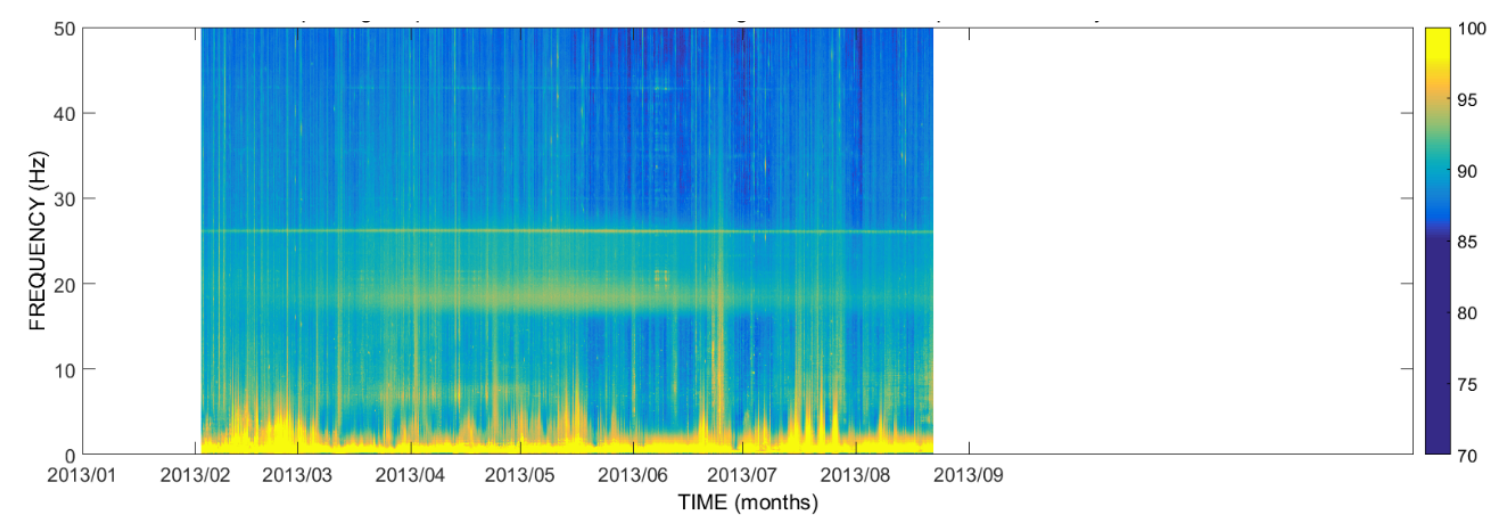

C5

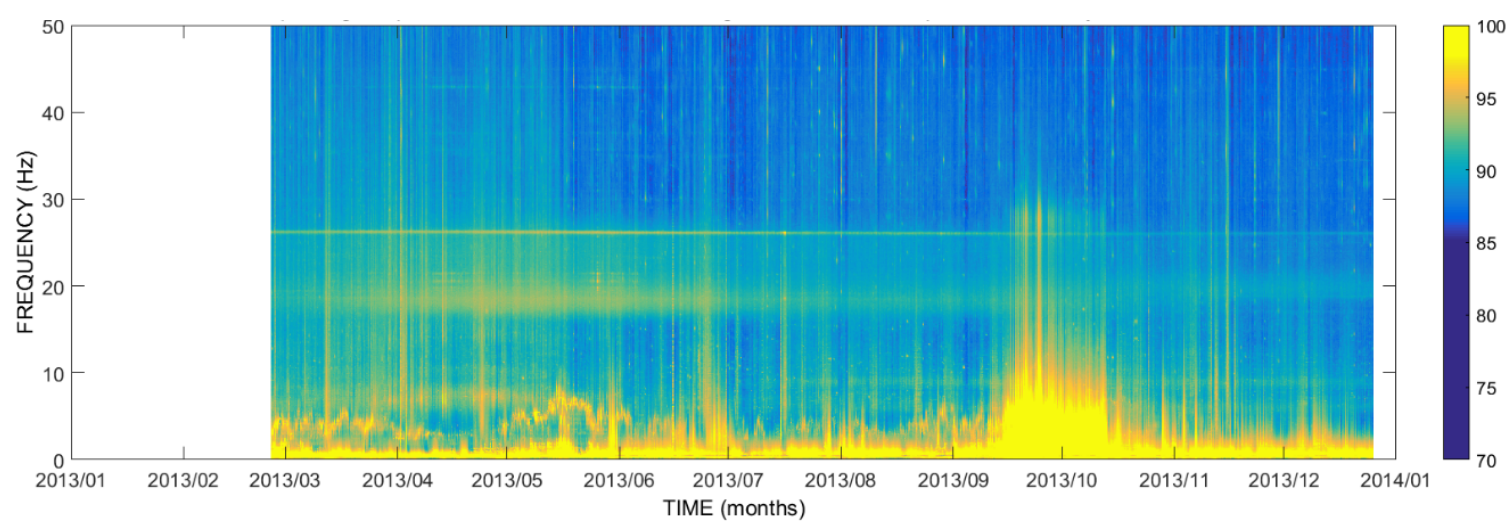

C4

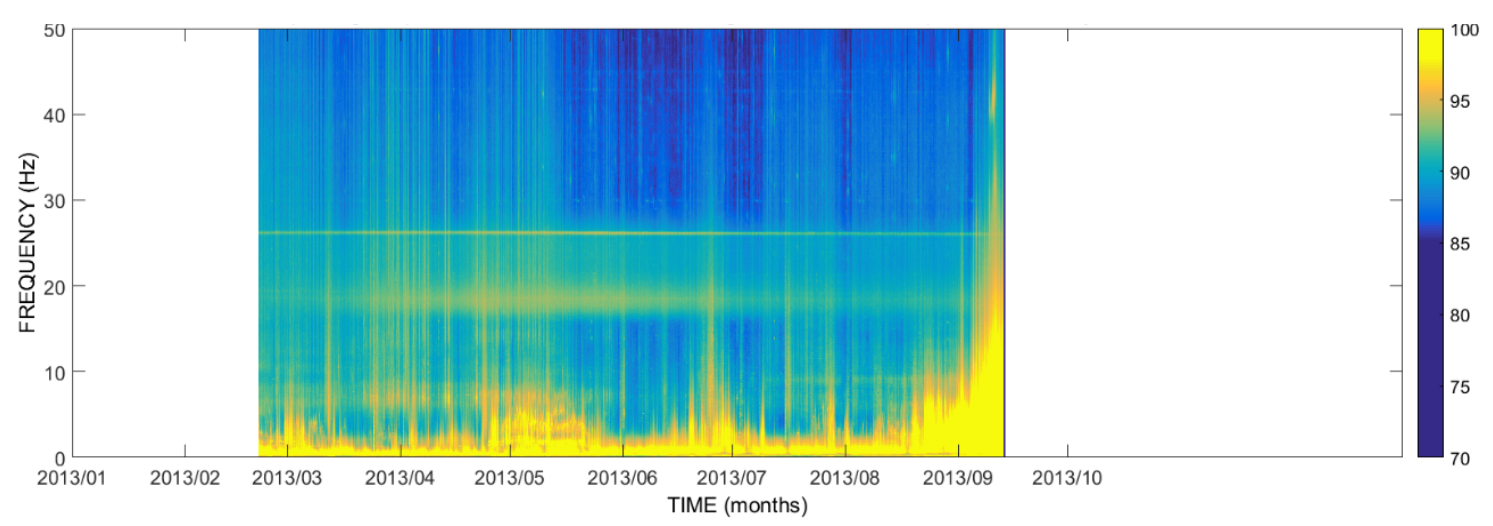

Figure 3: Long term spectrograms at sites C2 (top), C5 (middle) and C4 (bottom). Spectrogram parameters: FFT window 120 s, averaging window 6 h, $50 \%$ overlap. 
Samaran et al., 2019, Marine Mammal Science, doi: 10.1111/mms.12559

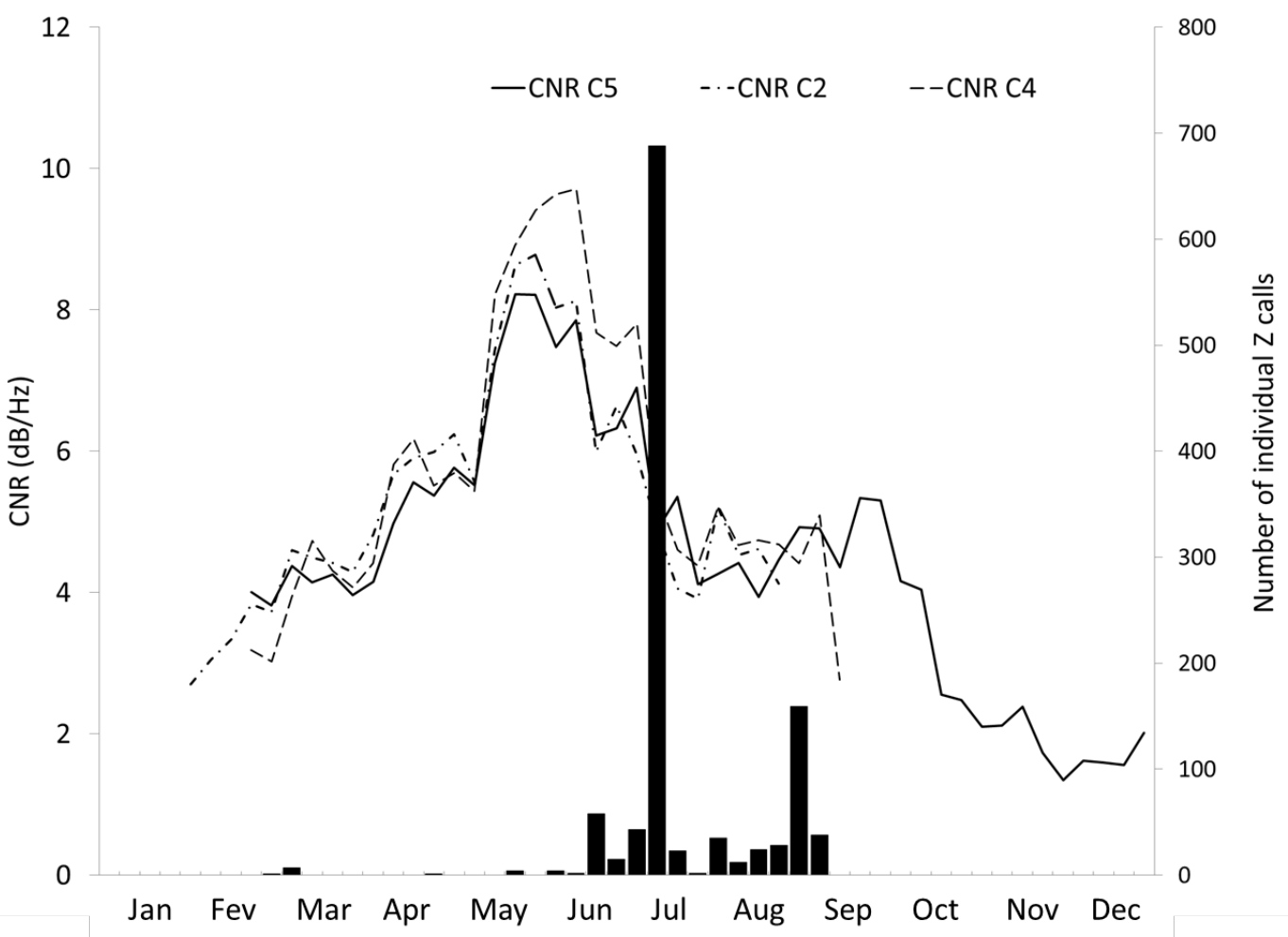

Figure 4: Chorus to Noise-without-chorus Ratio (CNR) level for all sites and weekly number of Z-calls detected at the $\mathrm{C} 5$ station over the available weeks of data. 